\title{
First report of pyracantha dieback caused by Trichothecium roseum in Iran
}

\author{
Saman Firouzianbandpey ${ }^{1} \cdot$ Mohammad-Ali Tajik Ghanbari $^{2} \cdot$ Hakimeh Ziaie Juybari ${ }^{2} \cdot$ Mojtaba Dehghan-Niri $^{2}$. \\ Esmaeil Basavand ${ }^{1}[$ ]
}

Received: 30 October 2020 / Accepted: 22 January 2021 / Published online: 15 February 2021

(c) Società Italiana di Patologia Vegetale (S.I.Pa.V.) 2021

Keyword Trichothecium roseum $\cdot$ Pyracantha dieback $\cdot$ Rosaceae

Scarlet firethorn (Pyracantha coccinea M. Roem.) is an evergreen shrub belonging to the Rosaceae family. In 2015, P. coccinea plants exhibited dieback disease in Yazd province (central province of Iran). The main disease symptoms included progressive death of shoot tips and weak plants (the incidence of the disease was about $40 \%$ ). From symptomatic plants, samples were collected and transferred to the laboratory. After superficially disinfection with $1 \%$ sodium hypochlorite, the symptomatic samples were plated on potato dextrose agar (PDA) medium and incubated at $28 \pm 2{ }^{\circ} \mathrm{C}$ for 5 days (Basavand et al. 2020). The fungal colonies were pink-to-white and hyaline hyphae in appearance. Conidiophores were simple or branched and ellipsoidal or pyriform conidia (measured 15.4 to $19.2 \times 7$ to $10.2 \mu \mathrm{m}$ ) formed in basipetal chains. These isolates were recognized as Trichothecium roseum (Pers.) Link based on morphological features (Wright et al. 2007). Genomic DNA of a reference isolate was extracted and the (ITS) region was amplified and sequenced (White et al. 1990). Sequence analysis (GenBank accession No. KR364570) with BLAST indicated the highest similarity (100\%) with T. roseum isolates deposited in GenBank. Pathogenicity of isolates was tested on $P$. coccinea by inoculating three twigs from two plants in a greenhouse at $25 \pm 2{ }^{\circ} \mathrm{C}$. Mycelial plugs, $0.5 \mathrm{~cm}$ in diameter, were placed on surface-scratched twigs and control plants were inoculated with agar plugs. Two weeks following the appearance of dieback-like symptoms, the isolates inoculated

Esmaeil Basavand

e.basavand@vru.ac.ir

1 Department of Plant Pathology, Vali-E-Asr University of Rafsanjan, Rafsanjan, Iran

2 Department of Plant Pathology, Sari Agricultural Sciences and Natural Resources University, Sari, Iran were re-isolated. To our knowledge, this is the first report of $T$. roseum on $P$. coccinea in Iran and worldwide.

Acknowledgments This research was supported by, the Vice Chancellor of Research and Technology grant at the Sari Agricultural Sciences and Natural Resources University, Iran.

\section{Declarations}

Conflict of interest The authors declare no conflict of interest.

\section{References}

Basavand E, Pakdin-Parizi A, Mirhosseini HA, Dehghan-Niri M (2020) Occurrence of leaf spot disease on date palm caused by Neopestalotiopsisclavispora in Iran. J Plant Pathol 102:959. https://doi.org/10.1007/s42161-020-00530-5

White TJ, Burns T, Lee S, Taylor J (1990) Amplification and direct sequencing of fungal ribosomal genes for phylogenetics. In: Innis MA,Gelfand DH, Shinsky J, White TJ, eds. PCR protocols. A guide to methods and applications. San Diego, CA, USA: Academic Press, pp. 315-322

Wright ER, Pizzingrilli P, Caligaris MV, Cabral D (2007) Rose Dieback Caused by Trichotheciumroseum in Argentina. Plant Dis 91:631. https://doi.org/10.1094/PDIS-91-5-0631C

Publisher's Note Springer Nature remains neutral with regard to jurisdictional claims in published maps and institutional affiliations. 